\title{
Erratum to: Optimal Capture of a Tumbling Object in Orbit Using a Space Manipulator
}

\section{Angel Flores-Abad • Lin Zhang •}

Zheng Wei · Ou Ma

Published online: 9 November 2016

(C) Springer Science+Business Media Dordrecht 2016

\section{Erratum to: J Intell Robot Syst \\ DOI 10.1007/s10846-016-0417-1}

The original version on this paper contained an error.

The $\tau$ shown in equation 11 should be changed to $\dot{\theta}$. The correct formula is given below.

$$
\mathbf{x}=\left[\begin{array}{l}
\mathbf{x}_{1} \\
\mathbf{x}_{2}
\end{array}\right]=\left[\begin{array}{c}
\boldsymbol{\theta} \\
\dot{\theta}
\end{array}\right]
$$

The online version of the original article can be found at http://dx.doi.org/10.1007/s10846-016-0417-1.

\footnotetext{
A. Flores-Abad $(\bowtie)$

Mechanical Engineering Department, University of Texas at El Paso, El Paso, TX 79968, USA

e-mail: afloresabad@utep.edu

L. Zhang · O. Ma

Department of Mechanical and Aerospace Engineering, New Mexico State University, Las Cruces, NM 88003, USA

Z. Wei

Department of Mathematics and Statistics, University

of Massachusetts Amherst, Amherst, MA 01002, USA
} 